\title{
man \\ Obesity as a Risk Factor for Hypertension and Diabetes among Truck Drivers in a Logistics Company, South Africa
}

\author{
Perpetua Modjadji ${ }^{1, *} \mathbb{*}$, Morongwa Bokaba ${ }^{1}$, Kebogile Elizabeth Mokwena ${ }^{1}\left(\mathbb{D}\right.$, Tshimangadzo Selina Mudau ${ }^{2} \mathbb{D}$, \\ Kotsedi Daniel Monyeki ${ }^{3}$ and Peter Modupi Mphekgwana ${ }^{4}$ (I) \\ 1 Department of Public Health, School of Health Care Sciences, Sefako Makgatho Health Sciences University, \\ Ga-Rankuwa MEDUNSA, Pretoria 0204, South Africa; morongs28@gmail.com (M.B.); \\ kebogile.mokwena@smu.ac.za (K.E.M.) \\ 2 Department of Nursing Science, School of Health Care Sciences, Sefako Makgatho Health Sciences University, \\ Ga-Rankuwa MEDUNSA, Pretoria 0204, South Africa; selina.mudau@smu.ac.za \\ 3 Department of Physiology and Environmental Health, University of Limpopo, Polokwane 0700, South Africa; \\ kotsedi.monyeki@ul.ac.za \\ 4 Research Administration and Development, University of Limpopo, Polokwane 0700, South Africa; \\ peter.mphekgwana@ul.ac.za \\ * Correspondence: Perpetua.modjadji@smu.ac.za; Tel.: +27-12-521-3664
}

check for updates

Citation: Modjadji, P.; Bokaba, M.; Mokwena, K.E.; Mudau, T.S.; Monyeki, K.D.; Mphekgwana, P.M. Obesity as a Risk Factor for Hypertension and Diabetes among Truck Drivers in a Logistics Company, South Africa. Appl. Sci. 2022, 12, 1685 https://doi.org/10.3390/ app12031685

Academic Editor: Tandi Matsha

Received: 18 November 2021

Accepted: 17 December 2021

Published: 7 February 2022

Publisher's Note: MDPI stays neutral with regard to jurisdictional claims in published maps and institutional affiliations.

Copyright: (C) 2022 by the authors. Licensee MDPI, Basel, Switzerland. This article is an open access article distributed under the terms and conditions of the Creative Commons Attribution (CC BY) license (https:// creativecommons.org/licenses/by/ $4.0 /)$.

\begin{abstract}
Despite the occupational nature of truckers predisposing them to cardiovascular diseases and risk factors, data is scarce on their prevalence of obesity and its association with developing hypertension (HBP) and diabetes in South Africa. Extracted from the original cross-sectional study of a sample of 312 employees in a logistics company, a census of 96 male truckers was used to determine the prevalence of obesity and its association with HBP and diabetes. WHO STEPwise approach was used to collect data, including systolic (SBP) and diastolic (DBP) blood pressure and anthropometry measurements. HBP is defined as SBP/DBP $\geq 140 / 90 \mathrm{mmHg}$, overweight/obesity as $\mathrm{BMI} \geq 25 \mathrm{~kg} / \mathrm{m}^{2}$, abdominal obesity by waist circumference as $\mathrm{WC} \geq 90 \mathrm{~cm}$, waist-to-hip-ratio as WHR $\geq 0.90$, and waist-to-height ratio as WHtR $\geq 0.5$. Data were analysed using SPSS 22. The mean age of truckers was 46 years, 29\% were smokers, and 57\% alcohol users, while $26 \%$ were physically inactive. The prevalence of overweight $(44 \%)$ and obesity $(30 \%)$ were observed, while abdominal obesity was high; WC (59\%), WHR (65\%), and WHtR (80\%). HBP (57\%) was prevalent and diabetes was $14 \%$. The odds of developing HBP were high for obese truckers by WC [AOR $=4.68$; $\mathrm{CI}=1.92-11.34)$ ] and by WHtR [AOR = 5.49 CI = 1.74-17.27), while diabetes was associated with WHR $(A O R=1.19 ; C I=1.19-31.21)$. This study showed an associative link between obesity, HBP, and diabetes among the truckers, which is informative for a relevant prevention programme tailored to their needs.
\end{abstract}

Keywords: overweight/obesity; abdominal obesity; hypertension; diabetes; truck drivers; logistics company; South Africa

\section{Introduction}

South Africa has recorded over 70,000 truck drivers in transport and logistics companies $[1,2]$. Truck drivers work for long hours delivering products across the country and borders [3]. Although the trucking industry contributes majorly to the economy and social development of the nation [4], truck driving is considered as one of the most dangerous occupations, giving rise to unfavourable health outcomes [5,6]. Truck drivers work in an environment which provides them with restricted chances to have a healthy lifestyle [7]. Truck drivers are subjected to unhealthy diets because of easy access to unhealthy food, in addition to a sedentary lifestyle, which predisposes them to the development of overweight/obesity [5,8]. Hence, overweight/obesity is an alarming health risk factors among truck drivers and might lead to hypertension (HBP), diabetes, and other health conditions [9-11]. 
According to $\mathrm{WHO}$, overweight/obesity is defined as excessive fat accumulation predisposing to health risks, and has become an escalating epidemic throughout the world [12,13]. Alarming rates of obesity have been observed (62\%) [14]; in South Africa, obesity prevalence is on the rise relative to other African countries [15-17]. The South African Health and Demographic Survey [18] has reported a prevalence of overweight/obesity among men at $31 \%$ by body mass index (BMI), $9 \%$ by waist circumference (WC), and $35 \%$ by waist-to-height ratio (WHtR). Although, overall overweight/obesity (BMI $\geq 25 \mathrm{~kg} / \mathrm{m}^{2}$ ) is most generally assessed by BMI and poses a health threat, body fat distribution contributes to health conditions $[19,20]$. Abdominal obesity using WC, waist-to-hip ratio (WHR), and WHtR has been recognised as an independent risk factor for cardio-metabolic diseases than general obesity. Independent of BMI, studies have shown a strong association between obesity markers and cardiovascular diseases, such as HBP and type 2 diabetes mellitus (T2D) [21-23].

HBP is a public health burden and a risk factor for cardiovascular diseases [24-26]. Globally, HBP account for 9.4 million deaths each year [27,28]. During 2015 to 2020, studies in South Africa estimated the prevalence of HBP among men to be between $17 \%$ and $49.5 \%$ [29-31]. The country is faced with a growing burden of HBP, concurrent with a rapid increase of T2D (i.e., raised glucose levels), another major source of morbidity and mortality, collectively owing to epidemiological transition, poor diets and inactive lifestyle [32-34]. T2D pooled prevalence of $15.25 \%$ has been reported in South Africans aged 25 years and older, irrespective of certain demographic factors, as well as diagnostic test and study design [35]. T2D and HBP overlap in the population and in most cases, the advancement of hypertension and T2D advance with time [26].

It is clear that truck drivers are essential employees contributing to the country's economy $[2-4,36]$. In this wise, studies from several countries, including Ethiopia, Nigeria, and Mexico have confirmed that obesity is high and associated with HBP, demographic, behavioural, and occupational factors $[8,37,38]$. However, in South Africa, data is scarce among commercial drivers, including truckers, which focuses on their healthcare and health status [2,36], HIV and sexually transmitted diseases [39-42], with minimal research on hypertension and T2D, and associated factors [43,44]. It is worth noting that noncommunicable diseases (NCDs), inclusive of cardiovascular diseases, are prevalent [29,45] and/or co-exist with communicable (e.g., HIV) diseases among different populations in South Africa [17,46,47].

In spite of the occupational nature of truckers predisposing them to cardiovascular diseases and risk factors [36], there is scarcity of data on the prevalence of general obesity and abdominal obesity and their association with developing these cardiovascular diseases among truckers in South Africa. It is imperative to improve work related wellbeing of truck drivers in general, as reiterated by other researchers $[2,36]$. Therefore, this study was designed to assess the relationship of obesity (using BMI, WC, WHR, and WHtR) with HBP and diabetes among male truck drivers in a logistics company in Midrand of Gauteng Province, South Africa. In the midst of limited research in South Africa, this study will contribute knowledge in relation to the concept studied. Understanding this relationship is necessary to inform health programmes in the company, tailored to the needs of truck drivers, to prevent overweight/obesity and ultimately reducing cardiovascular consequences, although cardiovascular diseases are multifactorial [48].

\section{Materials and Methods}

\subsection{Study Design and Population}

This paper is extracted from the original cross-sectional study that determined the prevalence of undiagnosed HBP and associated factors among employees of a logistics company in Midrand of Gauteng Province, South Africa. The company's location and the purpose have been discussed in details, in the original study of Bokaba et al. [45]. Briefly, this logistics company is situated in Midrand, a business hub of companies in the Gauteng Province of South Africa, and is a bulk cold storage enterprise transporting food 
in refrigerated primary transport to retailers, and has a wellness program organised twice a year [45]. There are 1650 employees in this particular logistics company and the original study calculated a representative sample of 312 using Rao software sample calculator [49], which considered the total population size of employees, a 5\% margin of error, and $95 \%$ confidence. A systematic random sampling was used to select employees from a headcounts list in alphabetical order. The original study excluded employees who had previously been diagnosed with hypertension/chronic diseases and were on medication at the time of the study, as well as female employees who indicated that they were pregnant [45].

For this paper, a census sample of male truck drivers was taken out of the original sample. This was motivated by the fact that in the original paper, truck drivers had a higher prevalence of HBP and were more likely to be obese compared to other employees [45]. Research shows that the transport industry exposes truck drivers to risk of devastating health conditions $[5,6,8]$. Data is scarce on the health status of the truck driver [2]; however, literature documents explicitly that truck drivers work under physically challenging circumstances, predisposing to health risks like HBP and diabetes $[7,9,11,50]$. Considering this universal concept, we singled out all the 96 truck drivers from the original study [45].

\subsection{Data Collection and Procedures}

In the original study, the main researcher collected data using a modified version of WHO STEPwise questionnaire [51] under the three major items: the demographic, behavioural data, and physical measurements. Demographic and behavioural data entailed occupation (i.e., job description and working shifts), age, marital status, education level, smoking and alcohol use, fruit, vegetables, salt consumption, physical activity, diabetes status, and family history of HBP (see Supplementary Material from the original study). The questionnaire was tested for validity and reliability using language translators from English to IsiZulu, content and face validity, and a pilot study; the results of the pilot study were not included in the main study [45].

The original study further collected physical measurements in a form of blood pressure and anthropometry [45]. Standard procedures were adhered to during measurements [52] using a digital blood pressure monitor, electronic weighing scale, stadiometer for height, and a tape measure for waist and hip circumferences. HBP was defined as the average of three systolic blood pressures (SBP) of $\geq 140 \mathrm{mmHg}$ and diastolic blood pressure (DBP) of $\geq 90 \mathrm{mmHg}$, or history of HBP or both, and studied the overall prevalence [53]. Body weight was measured from a participant wearing light clothes, and to the nearest $0.1 \mathrm{~kg}$ in a standing position using a calibrated smart D-quip electronic scale, and height was measured to the nearest $0.1 \mathrm{~cm}$ by a stadiometer in a standing position without shoes and with closed feet. The waist circumference (WC) was measured at the level of the umbilicus and hip circumference $(\mathrm{HC})$ at the widest part of the buttocks using a non-elastic tape. The body mass index (BMI) was categorized as: underweight $\left(\mathrm{BMI}<18.5 \mathrm{~kg} / \mathrm{m}^{2}\right)$, normal $\left(18.5-24.9 \mathrm{~kg} / \mathrm{m}^{2}\right)$, overweight $\left(25.0-29.9 \mathrm{~kg} / \mathrm{m}^{2}\right)$, and obese $\left(\geq 30 \mathrm{~kg} / \mathrm{m}^{2}\right)$. However, during data analysis, overweight and obesity were combined, and expressed either as overweight/obesity or obesity. Abdominal obesity was defined as having a WC $\geq 90 \mathrm{~cm}$, WHR $\geq 0.90$, and WHtR $\geq 0.5[54,55]$.

\subsection{Data Analysis}

Data were analysed using the Statistical Package for Social Science (SPSS) version 22. Data were expressed as mean/percentage ( $95 \mathrm{CI} \%)$. A Chi-square test and Fisher's exact test were used to determine the association between obesity and cardio-metabolic factors. The relationship of obesity with HBP and diabetes was determined using adjusted logistic regression analysis. The Kappa statistics was used to assess the degree of agreement of anthropometric markers to identify obesity. The statistical significance was set at $p<0.05$, and $95 \%$ confidence interval. 


\subsection{Ethical Consideration}

The study was approved by the Sefako Makgatho Health Sciences University Research and Ethics Committee, South Africa (SMUREC/H/46/2019: PG), in accordance with Helsinki II Declaration [56]. Permission to conduct the study was granted by the clinic manager of the Logistics company.

\section{Results}

A census sample of 96 truck drivers was obtained and the mean age was 46 years (44.56; 47.85). Mean weight and height were $80.86 \mathrm{~kg}$ and $170.90 \mathrm{~cm}$, respectively, ranging from 77.82 to $83.91 \mathrm{~kg}$ and 169.34 to $172.47 \mathrm{~cm}$, respectively. Among the total number of participants, the mean SBP and DBP of the study population were $140.96 \mathrm{mmHg}$ and $86.41 \mathrm{mmHg}$, respectively. The overall prevalence of hypertension and diabetes were found to be $57 \%$ and $14 \%$, respectively. The results further showed that $29 \%$ of truck drivers were smoking, while $44 \%$ and $30 \%$ of them were overweight and obese, respectively, with an overall overweight/obesity of $74 \%$. About $26 \%$ were physically active (Table 1).

Table 1. Descriptive statistics of cardio-metabolic factor amongst logistic company truck drivers.

\begin{tabular}{lc}
\hline Cardiometabolic Factor & Mean/Percentage (95\% CI) \\
\hline Age (years) & $46.21(44.56 ; 47.85)$ \\
\hline Weight $(\mathrm{kg})$ & $80.86(77.82 ; 83.91)$ \\
\hline Height $(\mathrm{cm})$ & $170.90(169.34 ; 172.47)$ \\
\hline BMI $\left(\mathrm{kg} / \mathrm{m}^{2}\right)$ & $27.64(26.73 ; 28.55)$ \\
$\quad$ Normal $(\%)$ & $26 \%(18 ; 36)$ \\
Overweight $(\%)$ & $44 \%(34 ; 54)$ \\
Obesity $(\%)$ & $30 \%(22 ; 40)$ \\
\hline Raised SBP (mmHg) & $140.96(137.74 ; 144.19)$ \\
\hline Raised DBP (mmHg) & $86.41(84.21 ; 88.61)$ \\
\hline Hypertension (yes) & $57 \%(47 ; 67)$ \\
\hline Diabetes (yes) & $14 \%(9 ; 23)$ \\
\hline Smoking (yes) & $29 \%(21 ; 39)$ \\
\hline Alcohol use (yes) & $57 \%(47 ; 67)$ \\
\hline Physical active (yes) & $26 \%(18 ; 36)$ \\
\hline BMI stands for body mass index; SBP stand for systolic blood pressure; and $\mathrm{DBP}$ stands for diastolic blood pressure.
\end{tabular}

The prevalence of obesity by cardio-metabolic risk factors is shown in Table 2. Comparable between all four groups, a higher prevalence of smoking was observed in both BMI, WHR, and WHtR groups, and a higher prevalence of diabetes and hypertension was also observed in all obesity groups.

In Table 3, Pearson correlation coefficients were used to measure the association between variables of cardio-metabolic and obesity (by BMI, WC, WHR, and WHtR) amongst male truck drivers. There were significant associations of hypertension with BMI $(p$-value $=0.042)$, WC $(p$-value $=0.001)$, and WHtR $(p$-value $=0.002)$ among truck drivers, while no association was observed with diabetes in this case. Raised SBP was significantly associated with WC and WHtR (Table 3). 
Table 2. Prevalence of cardio-metabolic factors distributed by obesity amongst logistic company truck drivers.

\begin{tabular}{|c|c|c|c|c|c|c|c|c|}
\hline \multirow[t]{2}{*}{ Cardiometabolic Factors } & \multicolumn{2}{|c|}{ Obesity Classified by BMI } & \multicolumn{2}{|c|}{ Obesity Classified by WC } & \multicolumn{2}{|c|}{ Obesity Classified by WHR } & \multicolumn{2}{|c|}{ Obesity Classified by WHtR } \\
\hline & No & Yes & No & Yes & No & Yes & No & Yes \\
\hline \multicolumn{9}{|l|}{ Age groups (years) } \\
\hline $30-40$ & $37 \%(20 ; 57)$ & $63 \%(43 ; 79)$ & $44 \%(27 ; 64)$ & $56 \%(36 ; 73)$ & $37 \%(21 ; 57)$ & $63 \%(43 ; 79)$ & $19 \%(8 ; 38)$ & $81 \%(62 ; 92)$ \\
\hline $41-50$ & $19 \%(9 ; 33)$ & $81 \%(67 ; 91)$ & $40 \%(25 ; 55)$ & $60 \%(45 ; 74)$ & $26 \%(15 ; 41)$ & $74 \%(59 ; 85)$ & $19 \%(9 ; 33)$ & $81 \%(67 ; 91)$ \\
\hline$>50$ & $27 \%(13 ; 47)$ & $73 \%(53 ; 87)$ & $38 \%(22 ; 59)$ & $62 \%(41 ; 78)$ & $50 \%(31 ; 69)$ & $50 \%(31 ; 69)$ & $23 \%(12 ; 43)$ & $77 \%(56 ; 89)$ \\
\hline Smoking (yes) & $32 \%(17 ; 52)$ & $67 \%(48 ; 83)$ & $50 \%(32 ; 68)$ & $50 \%(32 ; 68)$ & $39 \%(23 ; 59)$ & $61 \%(41 ; 77)$ & $25 \%(12 ; 0.45)$ & $75 \%(55 ; 88)$ \\
\hline Alcohol use (yes) & $23 \%(13 ; 35)$ & $78 \%(65 ; 87)$ & $35 \%(23 ; 48)$ & $65 \%(52 ; 77)$ & $38 \%(26 ; 52)$ & $62 \%(48 ; 74)$ & $15 \%(7 ; 0.27)$ & $85 \%(73 ; 93)$ \\
\hline Physical active (no) & $22 \%(14 ; 34)$ & $78 \%(66 ; 86)$ & $38 \%(27 ; 50)$ & $62 \%(49 ; 73)$ & $37 \%(26 ; 49)$ & $63 \%(51 ; 74)$ & $19 \%(12 ; 0.31)$ & $80 \%(69 ; 88)$ \\
\hline Raised SBP & $19 \%(10 ; 32)$ & $81 \%(68 ; 89)$ & $26 \%(16 ; 40)$ & $74 \%(59 ; 84)$ & $30 \%(19 ; 44)$ & $70 \%(56 ; 81)$ & $10 \%(4 ; 0.21)$ & $90 \%(78 ; 96)$ \\
\hline Raised DBP & $21 \%(11 ; 37)$ & $79 \%(63 ; 89)$ & $29 \%(17 ; 46)$ & $71 \%(54 ; 83)$ & $29 \%(17 ; 46)$ & $71 \%(54 ; 83)$ & $11 \%(4 ; 0.25)$ & $89 \%(75 ; 96)$ \\
\hline Diabetes (yes) & $14 \%(3 ; 45)$ & $86 \%(55 ; 97)$ & $29 \%(11 ; 58)$ & $71 \%(42 ; 89)$ & $21 \%(6 ; 51)$ & $79 \%(49 ; 93)$ & $8 \%(0.9 ; 4)$ & $92 \%(61 ; 99)$ \\
\hline Hypertension (yes) & $19 \%(9 ; 31)$ & $81 \%(69 ; 90)$ & $25 \%(15 ; 39)$ & $75 \%(61 ; 84)$ & $29 \%(18 ; 43)$ & $71 \%(57 ; 82)$ & $10 \%(4 ; 20)$ & $90 \%(79 ; 96)$ \\
\hline $\mathrm{n}(\%)$ & $25(26 \%)$ & $71(74 \%)$ & $39(41 \%)$ & $57(59 \%)$ & $34(35 \%)$ & $62(65 \%)$ & $19(20 \%)$ & $77(80 \%)$ \\
\hline
\end{tabular}

BMI stands for body mass index; WC for waist circumference; WHR for waist hip ratio; WHtR for waist-height-ratio; SBP for systolic blood pressure; and DBP for diastolic blood pressure. 
Table 3. Association between variables of cardio-metabolic and obesity (by BMI, WC, WHR and WHtR) amongst male truck drivers.

\begin{tabular}{ccccc}
\hline Cardiometabolic Factor & Obesity by BMI & Obesity by WC & Obesity by WHR & Obesity by WHtR \\
\hline Age & 0.230 & 0.889 & 0.118 & 0.886 \\
\hline Smoking & 0.382 & 0.230 & 0.611 & 0.411 \\
\hline Alcohol use & 0.275 & 0.160 & 0.512 & 0.135 \\
\hline Physical active & 0.187 & 0.383 & 0.678 & 0.976 \\
\hline Raised SBP & 0.075 & $0.002 *$ & 0.234 & 0.065 \\
\hline Raised DBP & 0.367 & 0.059 & 0.283 & 0.199 \\
\hline Diabetes & 0.278 & 0.320 & 0.236 & 0.133 \\
\hline Hypertension & $0.042^{*}$ & $0.001 *$ & $0.02 *$ & \\
\hline
\end{tabular}

BMI stands for body mass index; SBP stand for systolic blood pressure; DBP stands for diastolic blood pressure; and ${ }^{*} p$-value: significant at 0.05 .

Cohen's $k$ was estimated to see if there was an agreement between two obesity indicators: BMI-WC, BMI-WHR, BMI-WHtR, WC-WHR, WC-WHtR and WHR-WHtR. There was moderate agreement between obesity by BMI and WC, $\mathrm{k}=0.59(p<0.001)$, and obesity by WC and WHtR, $\mathrm{k}=0.48(p<0.001)$, indicating that 55 and 56 truck drivers, respectively, were obese. Obesity by BMI and WHtR had a significant agreement, $\mathrm{k}=0.65(p<0.001)$, but obesity by BMI and WC had a small agreement. However, there was a reasonable agreement between WC and WHR with a $45.8 \%$ agreement (Table 4 ).

Table 4. Agreement among anthropometric markers for identifying obesity.

\begin{tabular}{|c|c|c|c|}
\hline Two Obesity Indicators & Obesity & Kappa ( $p$-Value) & Agreement \\
\hline Obesity by BMI-WC & $55(57.3 \%)$ & $0.59(<0.001)^{* *}$ & Moderate \\
\hline Obesity by BMI-WHR & $50(52.1 \%)$ & $0.20(0.044)$ & Slight \\
\hline Obesity by BMI-WHtR & $68(70.8 \%)$ & $0.648(<0.001)^{* *}$ & Substantial \\
\hline Obesity by WC-WHR & $44(45.8 \%)$ & $0.32(0.002)$ & Fair \\
\hline Obesity by WC-WHtR & $56(58.3 \%)$ & $0.483(<0.001)^{* *}$ & Moderate \\
\hline Obesity by WHR-WHtR & $54(56.3 \%)$ & $0.216(0.022)$ & Fair \\
\hline
\end{tabular}

BMI stands for body mass index; WC for waist circumference; WHR for waist hip ratio; WHtR for waist-heightratio; and ${ }^{* *} p$-value: significant at less than 0.001 .

In Table 5, the odds of developing hypertension were over four times higher among truck drivers than the odds of non-obese truck drivers by WC $(\mathrm{AOR}=4.68 ; \mathrm{CI}=1.92$, 11.34) and WHtR (AOR $=5.49 \mathrm{CI}=1.74 ; 17.27)$, as compared to two times higher by $\mathrm{BMI}(\mathrm{AOR}=2.74 ; \mathrm{CI}=1.04,7.21)$ and $\mathrm{WHR}(\mathrm{AOR}=2.29 ; \mathrm{CI}=0.93,5.61)$. Diabetes was significantly associated with obesity by WHR (AOR $=1.19 ; \mathrm{CI}=1.19,31.21)$ only.

Table 5. Adjusted associations between hypertension, diabetes, and classification of obesity among truck drivers.

\begin{tabular}{clccc}
\hline Variable & Obesity by BMI & Obesity by WC & Obesity by WHR & Obesity by WHtR \\
\hline Diabetes (yes) & $2.81(0.49 ; 16.30)$ & $1.98(0.49 ; 8.04)$ & $6.01(1.19 ; 31.21)^{*}$ & $7.31(0.63 ; 84.70)$ \\
Hypertension (yes) & $2.74(1.04 ; 7.21)^{*}$ & $4.68(1.92 ; 11.34) *$ & $2.29(0.93 ; 5.61)^{*}$ & $5.49(1.74 ; 17.27) *$ \\
\hline
\end{tabular}

${ }^{*} p$-value: significant at 0.05 .

\section{Discussion}

Literature documents that truck drivers are predisposed to obesity due to the inactive environment of their occupation, making them susceptible to several devastating health conditions (e.g., hypertension and diabetes) $[5,6,8-11]$. Therefore, this study determined the prevalence of obesity and its association with hypertension and diabetes among truckers in a logistics company in South Africa. The study showed a moderate proportion of 
smoking among truckers, while alcohol use and physical inactivity were high. Overall overweight/obesity, abdominal obesity and hypertension were high among truckers, while diabetes was moderate. Hypertension was significantly associated with all abdominal obesity indicators, more so with WC and WHtR, and then followed by BMI and WHR. Elevated SBP was significantly related with WC and WHtR. On the other hand, diabetes was substantially related with abdominal obesity by WHR.

Overall overweight and obesity among truckers were 44\% and 30\%, respectively, making an overall overweight/obesity (by BMI) of 74\%. The high proportion of overweight/obesity is in line with $69 \%$ reported among truckers in South Africa [36], which is double the prevalence in the general population (31\%) [18]. The elevated proportion of overweight/obesity has also been reported in several developing countries, such as Ethiopia (56.5\%), India (40-55.5\%), and Brazil (79.2\%) [11,57,58], and developing countries, such as the USA (64-93.3\%) [9,59,60] and Germany (76\%) [61]. Researchers have alluded that high prevalence of overweight/obesity among truckers is attributed to junk foods, sugary foods, and drinks frequently consumed during long distance driving $[5,8]$. This is in addition to the socioeconomic (e.g., income), occupational (i.e., driving for long hours), and behavioral factors (i.e., alcohol use) [8,14,45]. This could justify the alarming prevalence and the variations of prevalence of overweight and obesity among studies, including the present study.

In addition, abdominal obesity by WC (59\%), WHR (65\%), and WHtR (80\%) were prevalent. Literature documents that BMI has a strong correlation with gold standard body fat, while WC, WHR, and WHtR are better indicators for assessing abdominal obesity [21-23,62]. The findings of this study classify truckers as being at a high or very high cardio-metabolic risk. This is consistent with a study of Lemke et al. [9], who reported 89\% of abdominal obesity among truckers, and further indicated that it is a valid measure of abdominal adiposity predisposing to cardio-metabolic risk. The concept of cardio-metabolic risk encompasses the increased likelihood of vascular events, and comprehends risk factors, such as hypertension, dyslipidemia, and smoking [63]. The current study further showed that the prevalence of diabetes was 14\%. Prominent cardio-metabolic risk factors, in addition to overweight/obesity, included smoking (29\%) and consuming alcohol (57\%), were observed in the present study, which were high compared to $11 \%$ and $9 \%$, respectively, in addition to physical inactivity reported among truck drivers in South Africa [36].

We found an alarmingly high prevalence of hypertension (57\%) among truck drivers in this study. A similar prevalence of $57 \%$ has been reported among commercial drivers in South Africa [43], while Lalla-Edwards et al. [36] reported a 36\% of hypertension among truckers in other South African provinces (i.e., Gauteng and Free State) between 2016 and 2017. The prevalence of hypertension recorded in this study is comparable to two studies in Hong Kong (57\%) [64] and Taiwan (56\%) [65] reported among commercial drivers, but higher than studies in Africa (9\% to 33\%) $[37,66,67]$ and several developing countries [68,69]. In addition, the current study reported a prevalence of $14 \%$ for diabetes, which is almost similar to the $16 \%$ prevalence among commercial drivers [44] in South Africa, but too high compared to $<3 \%$ reported among truckers in the country [36]. In addition, this prevalence is almost double compared to $8.3 \%$ overall prevalence of diabetes in the general population in South Africa [70]. Compared to developing countries, such as Hong Kong [64], Iran [68,71], and Brazil [72,73], the prevalence of diabetes among truckers in this study is higher, while Sangaleti et al. [11] reported an almost similar finding (16.4\%) among commercial taxi drivers in South Brazil. Uncontrolled and poorly controlled diabetes among truck drivers have been implicated to an increased risk of road accidents [74,75]. Both the prevalence of hypertension and diabetes among truck drivers in the current study may be related to their unhealthy lifestyle and illicit health behaviours associated with their job, similar to the suggestions of other researchers $[43,67]$.

In the present study, hypertension was significantly associated with all obesity indicators. Studies have found direct associations of hypertension with BMI, WC, WHR, and WHtR $[23,76,77]$. An upward trend in the incidence of hypertension with increas- 
ing BMI, WC, and WHtR has been reported in literature [78]. Obesity increases the risk of developing hypertension [79] due to the activation of the sympathetic nervous system, renin-angiotensin system, and sodium retention among other abnormalities [33,80]. Meanwhile, the current study further showed that diabetes was substantially related with abdominal obesity by WC and WHR. WC has been reported as a stronger anthropometric predictor of diabetes than BMI [81]. In addition, WHR has been reported as the mutual indicator for diabetes, subsequent to BMI, and correlates weakly with BMI compared to the correlation with WC $[82,83]$. Abdominal obesity leads to developing insulin resistance and glucose metabolism [84], which exposes to T2D and far ahead to hypertension; then, eventually causing cardiovascular diseases [85]. Hypertension and diabetes share similar metabolic pathways and risk factors, such as genetics, physical inactivity, dyslipidemia, insulin resistance, and obesity. These factors collectively contribute to the development of arterial stiffness, which promotes the development of hypertension [86,87]. Researchers have found that truck drivers are at increased risk of being overweight or obese, which is associated with developing hypertension and T2D [11,68,69].

In agreement with limited South African studies [36,43,44], the current study affirms an associative link between obesity, HBP, and diabetes among the truckers. Remarkably, the increased proportion of obesity and the associated cardio-metabolic complications, such as HBP and diabetes mellitus, is a drawback of years of efforts towards the attainment of the Sustainable Development Goal (SDG) three (3) of health and well-being and 10 of reducing inequality, since this leads to health complications and death [88]. Moreover, truck drivers contribute significantly in the economy of their families and the country.

\section{Limitations}

The limitations of this study are worth noting. First, the results of the cross-sectional design cannot report on causality, rather, inferences, considering that cardiovascular diseases are multifactorial. Continuing studies are useful to study the magnitude of the association. Second, the study used a census (i.e., all) sample of truckers who participated in the original study, which is small in nature and may affect the reliability of the results, leading to a higher variability. Nonetheless, our findings were comparable with limited available studies in South Africa, Africa, and developing countries on the subject studied. Third, the study did not collect psychosocial and biochemical data, hence, diabetes was self-reported. The appropriate method to diagnose diabetes is the use of capillary glycaemia; however, we were limited by budget constraints. Studies with budget resources should endeavor to collect all work-related data, from occupation, psychosocial, and blood sample for all-inclusive approach. Social desirability might have led to under-reporting on smoking and alcohol consumption, condoned by the use of dichotomous questions. Fourth, data collection took place at one site, hence, may not apply to truckers in other logistics companies in South Africa. Despite these noted weaknesses, our study provides important findings on the prevalence of obesity in association with hypertension and diabetes among truckers, adding to the limited data available in South Africa. Furthermore, multiple anthropometric and blood pressure measurements were obtained and the averages were used in data analysis. Participants with hypertension were advised to seek medical care from the in-house clinic available in this logistics company.

\section{Conclusions}

The prevalence of overall overweight/obesity and abdominal obesity among truck drivers in a logistic company in South Africa are alarming. Prominent risk factors for cardiovascular diseases were smoking and alcohol use, in addition to a sedentary lifestyle indicated by physical inactiveness. Overweight/obesity and abdominal obesity were associated with developing of hypertension and diabetes. This study provides useful information on the association of anthropometric indicators of obesity with hypertension and diabetes, which would be helpful for an effective prevention programme tailored for truckers. 
Supplementary Materials: The following are available online at https:/ / www.mdpi.com/article/ 10.3390/app12031685/s1, Questionnaire: Obesity as a Risk Factor for Hypertension and Diabetes among Truck Drivers in a Logistics Company, South Africa.

Author Contributions: Conceptualization, P.M. and M.B.; Formal analysis, P.M.M.; Investigation, M.B.; Methodology, P.M. and M.B.; Resources, M.B.; Software, P.M.M.; Supervision, P.M.; Writingoriginal draft, P.M. and P.M.M.; Writing-review \& editing, P.M., K.E.M., T.S.M. and K.D.M. All authors have read and agreed to the published version of the manuscript.

Funding: This research received no external funding. The study was self-funded.

Institutional Review Board Statement: The study was conducted according to the guidelines of the Declaration of Helsinki, and approved by the Institutional Review Board (or Ethics Committee) of the Sefako Makgatho Health Sciences University, South Africa, (SMUREC/H/46/2019: PG, approved on 7 March 2019).

Informed Consent Statement: Participation was voluntary and the participants provided written informed consents.

Data Availability Statement: The dataset for participants generated and analysed during the original study is available from the corresponding author upon reasonable request.

Acknowledgments: The author would like to thank the management of a company for allowing the in-house clinic to grant us the permission to conduct the study. We are also grateful to the truck drivers for their consent to participate in the study.

Conflicts of Interest: The authors declare no conflict of interest.

\section{References}

1. Lalla-Edward, S.; Gomez, G. Enroute to a healthy truck driver population. HIV Nurs. Matters 2015, 6, 20-23.

2. Lalla-Edward, S.T.; Matthew, P.; Hankins, C.A.; Venter, W.D.F.; Gomez, G.B. Healthcare for truck drivers: Assessing accessibility and appropriateness of South African Roadside Wellness Centres. J. Transp. Health 2018, 8, 63-72. [CrossRef]

3. Gomez, G.B.; Venter, W.D.; Lange, J.M.; Rees, H.; Hankins, C. North-South Corridor Demonstration Project: Ethical and Logistical Challenges in the Design of a Demonstration Study of Early Antiretroviral Treatment for Long Distance Truck Drivers along a Transport Corridor through South Africa, Zimbabwe, and Zambia. Adv. Prev. Med. 2013, 2013, 190190. [CrossRef] [PubMed]

4. Fourie, D.J.; Schoeman, R. The South African long distance trucking industry's response to the HIV/AIDS epidemic. S. Afr. J. Econ. Manag. Sci. 2006, 2, 196-206. [CrossRef]

5. Boyce, W.S. Does truck driver health and wellness deserve more attention? J. Transp. Health 2016, 3, 124-128. [CrossRef]

6. Korhan, O.; Nazerian, R.; Shakeri, E. Work Related Musculoskeletal Discomfort among Heavy Truck Drivers. Int. J. Occup. Saf. Ergon. JOSE 2018, 26, 233-244. [CrossRef]

7. Ng, M.K.; Yousuf, B.; Bigelow, P.L.; Van Eerd, D. Effectiveness of health promotion programmes for truck drivers: A systematic review. Health Educ. J. 2015, 74, 270-286. [CrossRef]

8. Yosef, T.; Bogale, B.; Destaw, A.; Weldu, A. The Burden of Overweight and Obesity among Long-Distance Truckers in Ethiopia. J. Obes. 2020, 2020, 4242789. [CrossRef]

9. Lemke, M.; Hege, A.; Perko, M.; Sönmez, S.; Apostolopoulos, Y. Work patterns, sleeping hours and excess weight in commercial drivers. Occup. Med. 2015, 65, 725-731. [CrossRef]

10. Mungreiphy, N.; Kapoor, S.; Sinha, R. Association between BMI, blood pressure, and age: Study among Tangkhul Naga tribal males of Northeast India. J. Anthropol. 2011, 2011, 748147. [CrossRef]

11. Sangaleti, C.T.; Trincaus, M.R.; Baratieri, T.; Zarowy, K.; Ladika, M.B.; Menon, M.U.; Miyahara, R.Y.; Raimondo, M.I.; Silveira, J.V.; Bortolotto, L.A. Prevalence of cardiovascular risk factors among truck drivers in the South of Brazil. BMC Public Health 2014, 14, 1063. [CrossRef] [PubMed]

12. WHO. Obesity Epidemic Puts Millions at Risk from Related Diseases. Press Release WHO/46. 1997. Available online: www.who. int/inf-prp1997/en/pr97-46.html (accessed on 22 October 2021).

13. WHO. Obesity. 2021. Available online: https://www.who.int/health-topics/obesity\#tab=tab_1 (accessed on 22 October 2021).

14. Ford, N.D.; Patel, S.A.; Narayan, K.V. Obesity in low-and middle-income countries: Burden, drivers, and emerging challenges. Annu. Rev. Public Health 2017, 38, 145-164. [CrossRef]

15. Modjadji, P. Socio-demographic Determinants of Overweight and Obesity Among Mothers of Primary School Children Living in a Rural Health and Demographic Surveillance System Site, South Africa. TOPHJ 2020, 13, 518-528. [CrossRef]

16. Debeila, S.; Modjadji, P.; Madiba, S. High prevalence of overall overweight/obesity and abdominal obesity amongst adolescents: An emerging nutritional problem in rural high schools in Limpopo Province, South Africa. Afr. J. Prim. Health Care Fam. Med. 2021, 13, 2596. [CrossRef] 
17. Mahlangu, K.; Modjadji, P.; Madiba, S. The Nutritional Status of Adult Antiretroviral Therapy Recipients with a Recent HIV Diagnosis; A Cross-Sectional Study in Primary Health Facilities in Gauteng, South Africa. Healthcare 2020, 8, 290. [CrossRef] [PubMed]

18. SouthAfricanDemographicAndHealthSurvey2016. Key Indicators Report. Statistics South Africa. 2017. Available online: https:/ / www.statssa.gov.za / publications/Report\%2003-00-09/Report\%2003-00-092016.pdf (accessed on 22 October 2021).

19. Bhaskaran, K.; Douglas, I.; Forbes, H.; dos-Santos-Silva, I.; Leon, D.A.; Smeeth, L. Body-mass index and risk of 22 specific cancers: A population-based cohort study of $5 \cdot 24$ million UK adults. Lancet 2014, 384, 755-765. [CrossRef]

20. Flegal, K.M.; Kit, B.K.; Orpana, H.; Graubard, B.I. Association of all-cause mortality with overweight and obesity using standard body mass index categories: A systematic review and meta-analysis. JAMA 2013, 309, 71-82. [CrossRef]

21. Czernichow, S.; Kengne, A.-P.; Huxley, R.R.; Batty, G.D.; De Galan, B.; Grobbee, D.; Pillai, A.; Zoungas, S.; Marre, M.; Woodward, $\mathrm{M}$. Comparison of waist-to-hip ratio and other obesity indices as predictors of cardiovascular disease risk in people with type-2 diabetes: A prospective cohort study from ADVANCE. Eur. J. Prev. Cardiol. 2011, 18, 312-319. [CrossRef]

22. Licata, G.; Argano, C.; Di Chiara, T.; Parrinello, G.; Scaglione, R. Obesity: A main factor of metabolic syndrome? Panminerva Med. 2006, 48, 77-85.

23. Liu, Y.; Tong, G.; Tong, W.; Lu, L.; Qin, X. Can body mass index, waist circumference, waist-hip ratio and waist-height ratio predict the presence of multiple metabolic risk factors in Chinese subjects? BMC Public Health 2011, 11, 35. [CrossRef]

24. Poulter, N.R.; Prabhakaran, D.; Caulfield, M. Hypertension. Lancet 2015, 386, 801-812. [CrossRef]

25. Stanaway, J.D.; Afshin, A.; Gakidou, E.; Lim, S.S.; Abate, D.; Abate, K.H.; Abbafati, C.; Abbasi, N.; Abbastabar, H.; Abd-Allah, F Global, regional, and national comparative risk assessment of 84 behavioural, environmental and occupational, and metabolic risks or clusters of risks for 195 countries and territories, 1990-2017: A systematic analysis for the Global Burden of Disease Study 2017. Lancet 2018, 392, 1923-1994.

26. Tsimihodimos, V.; Gonzalez-Villalpando, C.; Meigs, J.B.; Ferrannini, E. Hypertension and Diabetes Mellitus. Hypertension 2018, 71, 422-428. [CrossRef]

27. Mills, K.T.; Bundy, J.D.; Kelly, T.N.; Reed, J.E.; Kearney, P.M.; Reynolds, K.; Chen, J.; He, J. Global disparities of hypertension prevalence and control: A systematic analysis of population-based studies from 90 countries. Circulation 2016, 134, 441-450. [CrossRef] [PubMed]

28. Wang, Z.; Chen, Z.; Zhang, L.; Wang, X.; Hao, G.; Zhang, Z.; Shao, L.; Tian, Y.; Dong, Y.; Zheng, C. Status of hypertension in China: Results from the China hypertension survey, 2012-2015. Circulation 2018, 137, 2344-2356. [CrossRef]

29. Maimela, E.; Alberts, M.; Modjadji, S.E.; Choma, S.S.; Dikotope, S.A.; Ntuli, T.S.; Van Geertruyden, J.P. The Prevalence and Determinants of Chronic Non-Communicable Disease Risk Factors amongst Adults in the Dikgale Health Demographic and Surveillance System (HDSS) Site, Limpopo Province of South Africa. PLoS ONE 2016, 11, e0147926. [CrossRef]

30. Mphekgwana, P.M.; Malema, N.; Monyeki, K.D.; Mothiba, T.M.; Makgahlela, M.; Kgatla, N.; Makgato, I.; Sodi, T. Hypertension Prevalence and Determinants among Black South African Adults in Semi-Urban and Rural Areas. Int. J. Environ. Res. Public Health 2020, 17, 7463. [CrossRef]

31. Ntuli, S.T.; Maimela, E.; Alberts, M.; Choma, S.; Dikotope, S. Prevalence and associated risk factors of hypertension amongst adults in a rural community of Limpopo Province, South Africa. Afr. J. Prim. Health Care Fam. Med. 2015, 7, 847. [CrossRef]

32. Hall, J.E.; do Carmo, J.M.; da Silva, A.A.; Wang, Z.; Hall, M.E. Obesity-induced hypertension: Interaction of neurohumoral and renal mechanisms. Circ. Res. 2015, 116, 991-1006. [CrossRef] [PubMed]

33. Jiang, S.Z.; Lu, W.; Zong, X.F.; Ruan, H.Y.; Liu, Y. Obesity and hypertension. Exp. Ther. Med. 2016, 12, 2395-2399. [CrossRef] [PubMed]

34. Pheiffer, C.; Pillay-van Wyk, V.; Joubert, J.D.; Levitt, N.; Nglazi, M.D.; Bradshaw, D. The prevalence of type 2 diabetes in South Africa: A systematic review protocol. BMJ Open 2018, 8, e021029. [CrossRef] [PubMed]

35. Pheiffer, C.; Pillay-van Wyk, V.; Turawa, E.; Levitt, N.; Kengne, A.P.; Bradshaw, D. Prevalence of Type 2 Diabetes in South Africa: A Systematic Review and Meta-Analysis. Int. J. Environ. Res. Public Health 2021, 18, 5868. [CrossRef] [PubMed]

36. Lalla-Edward, S.T.; Fischer, A.E.; Venter, W.D.F.; Scheuermaier, K.; Meel, R.; Hankins, C.; Gomez, G.; Klipstein-Grobusch, K.; Draaijer, M.; Vos, A.G. Cross-sectional study of the health of southern African truck drivers. BMJ Open 2019, 9, e032025. [CrossRef]

37. Oyeniyi, O.S.; Ajayi, I.O. Prevalence of hypertension and associated risk factor among interstate commercial drivers in Jabi Park Abuja. Int. J. Med. Med. Sci. 2016, 8, 75-83.

38. Aguilar-Zinser, J.V.; Irigoyen-Camacho, M.E.; Ruiz-Garcia-Rubio, V.; Perez-Ramirez, M.; Guzman-Carranza, S.; CervantesValencia, L. Prevalance of overweight and obesity among professional bus drivers in Mexico. Gac. Med. Mex. 2007, 143, 21-25. [PubMed]

39. Delany-Moretlwe, S.; Bello, B.; Kinross, P.; Oliff, M.; Chersich, M.; Kleinschmidt, I.; Rees, H. HIV prevalence and risk in long-distance truck drivers in South Africa: A national cross-sectional survey. Int. J. STD AIDS 2014, 25, 428-438. [CrossRef]

40. Ramjee, G.; Gouws, E. Prevalence of HIV among truck drivers visiting sex workers in KwaZulu-Natal, South Africa. Sex. Transm. Dis. 2002, 29, 44-49. [CrossRef] [PubMed]

41. Mpata Mokgatle, M.; Madiba, S. Intentions to use patient-initiated partner notification and acceptability of provider-initiated partner notification for Sexually Transmitted Infections-A cross-sectional survey among minibus taxi drivers in Gauteng Province, South Africa. bioRxiv 2018. [CrossRef] 
42. Mokgatle, M.M.; Madiba, S. Risky sexual behaviour amidst predicament of acceptable sexually transmitted infection partner notification modalities: A cross-sectional survey amongst minibus taxi drivers in Gauteng Province, South Africa. S. Afr. Fam. Pract. (2004) 2020, 62, e1-e6. [CrossRef]

43. Adedokun, A.; Ter, G.; Owolabi, E.; Adeniyi, V.; Ajayi, A. Driving to Better Health: Screening for Hypertension and Associated Factors Among Commercial Taxi Drivers in Buffalo City Metropolitan Municipality, South Africa. Open Public Health J. 2017, 10, 303-312. [CrossRef]

44. Adedokun, A.O.; Ter Goon, D.; Owolabi, E.O.; Adeniyi, O.V.; Ajayi, A.I. Prevalence, awareness, and determinants of type 2 diabetes mellitus among commercial taxi drivers in buffalo city metropolitan municipality South Africa: A cross-sectional survey. Medicine 2019, 98, e14652. [CrossRef] [PubMed]

45. Bokaba, M.; Modjadji, P.; Mokwena, K.E. Undiagnosed Hypertension in a Workplace: The Case of a Logistics Company in Gauteng, South Africa. Healthcare 2021, 9, 964. [CrossRef] [PubMed]

46. Modjadji, P. Communicable and non-communicable diseases coexisting in South Africa. Lancet Glob. Health 2021, 9, e889-e890. [CrossRef]

47. Mengwai, K.; Madiba, S.; Modjadji, P. Low Disclosure Rates to Sexual Partners and Unsafe Sexual Practices of Youth Recently Diagnosed with HIV, Implications for HIV Prevention Interventions in South Africa. Healthcare 2020, 8, 253. [CrossRef]

48. Castelli, W.P. Cardiovascular disease and multifactorial risk: Challenge of the 1980s. Am. Heart J. 1983, 106, 1191-1200. [CrossRef]

49. Raosoftware Calulator. Available online: http://www.raosoft.com/samplesize.html (accessed on 22 January 2019).

50. Hege, A.; Lemke, M.K.; Apostolopoulos, Y.; Sönmez, S. Occupational health disparities among U.S. long-haul truck drivers: The influence of work organization and sleep on cardiovascular and metabolic disease risk. PLoS ONE 2018, 13, e0207322. [CrossRef]

51. WHO. The WHO STEPwise Approach to Surveillance of Noncommunicable Diseases (STEPS); World Health Organization: Geneva, Switzerland, 2003. Available online: https://www.who.int/ncd_surveillance/en/steps_framework_dec03.pdf (accessed on 10 January 2019).

52. Seedat, Y.K.; Rayner, B.L.; Veriava, Y. South African hypertension practice guideline 2014. Cardiovasc. J. Afr. 2014, 25, 288-294. [CrossRef] [PubMed]

53. Harada, K.; Karube, Y.; Saruhara, H.; Takeda, K.; Kuwajima, I. Workplace hypertension is associated with obesity and family history of hypertension. Hypertens. Res. 2006, 29, 969-976. [CrossRef] [PubMed]

54. Ashwell, M. Obesity risk: Importance of the waist-to-height ratio. Nurs. Stand 2009, 23, 49-54. [CrossRef]

55. WHO. Physical Status: The Use and Interpretation of Anthropometry; Report of a WHO Expert Committee; World Health Organization: Geneva, Switzerland, 1995.

56. Shrestha, B.; Dunn, L. The Declaration of Helsinki on Medical Research involving Human Subjects: A Review of Seventh Revision. J. Nepal Health Res. Counc. 2020, 17, 548-552. [CrossRef] [PubMed]

57. Rao, C.R.; Kumar, U.; Mishra, S.; Kamath, V. Screening for Non-Communicable Diseases among transport employees of a University: A descriptive analysis. Indian J. Community Health 2016, 28, 100-105.

58. Singaravel, S.; Kandaswamy, E. A cross sectional study on prevalence of obesity among bus drivers of metropolitan transport corporation limited, Chennai. Int. J. Community Med. Public Health 2017, 4, 4456-4459. [CrossRef]

59. Yeary, K.H.K.; Chi, X.; Lensing, S.; Baroni, H.; Ferguson, A.; Su, J.; Estabrooks, P.A.; Tate, D.; Linnan, L. Peer Reviewed: Overweight and Obesity Among School Bus Drivers in Rural Arkansas. Prev. Chronic Dis. 2019, 16, E61. [CrossRef] [PubMed]

60. Turner, L.M.; Reed, D.B. Exercise among commercial truck drivers. Aaohn J. 2011, 59, 429-436. [CrossRef]

61. Bschaden, A.; Rothe, S.; Schöner, A.; Pijahn, N.; Stroebele-Benschop, N. Food choice patterns of long-haul truck drivers driving through Germany, a cross sectional study. BMC Nutr. 2019, 5, 56. [CrossRef]

62. Zhang, W.; He, K.; Zhao, H.; Hu, X.; Yin, C.; Zhao, X.; Shi, S. Association of body mass index and waist circumference with high blood pressure in older adults. BMC Geriatr. 2021, 21, 260. [CrossRef]

63. Leiter, L.A.; Fitchett, D.H.; Gilbert, R.E.; Gupta, M.; Mancini, G.J.; McFarlane, P.A.; Ross, R.; Teoh, H.; Verma, S.; Anand, S. Cardiometabolic risk in Canada: A detailed analysis and position paper by the cardiometabolic risk working group. Can. J. Cardiol. 2011, 27, e1-e33. [CrossRef] [PubMed]

64. Siu, S.; Wong, K.; Lee, K.; Lo, Y.; Wong, C.; Chan, A.; Fong, D.; Lam, C. Prevalence of undiagnosed diabetes mellitus and cardiovascular risk factors in Hong Kong professional drivers. Diabetes Res. Clin. Pract. 2012, 96, 60-67. [CrossRef]

65. Wang, P.D.; Lin, R.S. Coronary heart disease risk factors in urban bus drivers. Public Health 2001, 115, 261-264. [CrossRef]

66. Erhiano, E.; Igbokwe, V.; El-Khashab, M.; Okolo, R.; Awosan, K. Prevalence of hypertension among commercial bus drivers in Sokoto, Sokoto State Nigeria. Int. J. Med. Med. Sci. 2015, 2, 34-39.

67. Odeyinka, O.T.; Ajayi, I.O. Prevalence of hypertension and diabetes and their determinants among commercial drivers in Ibadan metropolis, South-Western Nigeria. Niger. J. Cardiol. 2017, 14, 75.

68. Saberi, H.R.; Moravveji, A.R.; Fakharian, E.; Kashani, M.M.; Dehdashti, A.R. Prevalence of metabolic syndrome in bus and truck drivers in Kashan, Iran. Diabetol. Metab. Syndr. 2011, 3, 8. [CrossRef]

69. Shin, S.Y.; Lee, C.G.; Song, H.S.; Kim, S.H.; Lee, H.S.; Jung, M.S.; Yoo, S.K. Cardiovascular disease risk of bus drivers in a city of Korea. Ann. Occup. Environ. Med. 2013, 25, 34. [CrossRef] [PubMed]

70. Guariguata, L.; Whiting, D.R.; Hambleton, I.; Beagley, J.; Linnenkamp, U.; Shaw, J.E. Global estimates of diabetes prevalence for 2013 and projections for 2035. Diabetes Res. Clin. Pract. 2014, 103, 137-149. [CrossRef] [PubMed] 
71. Izadi, N.; Malek, M.; Aminian, O.; Saraei, M. Medical risk factors of diabetes mellitus among professional drivers. J. Diabetes Metab. Disord. 2013, 12, 23. [CrossRef]

72. dos Reis, L.A.P.; Costa, C.D.D.; Rodrigues, D.S.; de Alcântara, K.C. Obesity, hypertension and diabetes among truck drivers in the middle-west, Brazil. Biosci. J. 2017, 33, 485-493. [CrossRef]

73. Hirata, R.P.; Sampaio, L.M.M.; Leitao Filho, F.S.S.; Braghiroli, A.; Balbi, B.; Romano, S.; Insalaco, G.; Oliveira, L.V.F.d. General characteristics and risk factors of cardiovascular disease among interstate bus drivers. Sci. World J. 2012, 2012, 216702. [CrossRef] [PubMed]

74. de Grauw, W.J.; van de Lisdonk, E.H.; Behr, R.R.; van Gerwen, W.H.; van den Hoogen, H.J.; van Weel, C. The impact of type 2 diabetes mellitus on daily functioning. Fam. Pract. 1999, 16, 133-139. [CrossRef]

75. Distiller, L.A.; Kramer, B.D. Driving and diabetics on insulin therapy. S. Afr. Med. J. 1996, 86, $1018-1020$.

76. Garrison, R.J.; Kannel, W.B.; Stokes, J., III; Castelli, W.P. Incidence and precursors of hypertension in young adults: The Framingham Offspring Study. Prev. Med. 1987, 16, 235-251. [CrossRef]

77. Luz, R.H.; Barbosa, A.R.; d'Orsi, E. Waist circumference, body mass index and waist-height ratio: Are two indices better than one for identifying hypertension risk in older adults? Prev. Med. 2016, 93, 76-81. [CrossRef]

78. Chen, X.; Liu, Y.; Sun, X.; Yin, Z.; Li, H.; Deng, K.; Cheng, C.; Liu, L.; Luo, X.; Zhang, R.; et al. Comparison of body mass index, waist circumference, conicity index, and waist-to-height ratio for predicting incidence of hypertension: The rural Chinese cohort study. J. Hum. Hypertens. 2018, 32, 228-235. [CrossRef]

79. Borrell, L.N.; Samuel, L. Body mass index categories and mortality risk in US adults: The effect of overweight and obesity on advancing death. Am. J. Public Health 2014, 104, 512-519. [CrossRef] [PubMed]

80. Re, R.N. Obesity-related hypertension. Ochsner. J. 2009, 9, 133-136.

81. Group, D.S.; Nyamdorj, R. BMI compared with central obesity indicators in relation to diabetes and hypertension in Asians. Obesity 2008, 16, 1622-1635. [CrossRef] [PubMed]

82. Ohlson, L.O.; Larsson, B.; Svärdsudd, K.; Welin, L.; Eriksson, H.; Wilhelmsen, L.; Björntorp, P.; Tibblin, G. The influence of body fat distribution on the incidence of diabetes mellitus. 13.5 years of follow-up of the participants in the study of men born in 1913. Diabetes 1985, 34, 1055-1058. [CrossRef] [PubMed]

83. Wei, M.; Gaskill, S.P.; Haffner, S.M.; Stern, M.P. Waist circumference as the best predictor of noninsulin dependent diabetes mellitus (NIDDM) compared to body mass index, waist/hip ratio and other anthropometric measurements in Mexican Americans-a 7-year prospective study. Obes. Res. 1997, 5, 16-23. [CrossRef] [PubMed]

84. Pinto, G.; Beltrán-Sánchez, H. Prospective study of the link between overweight/obesity and diabetes incidence among Mexican older adults: 2001-2012. Salud Publica Mex. 2015, 57 (Suppl. 1), S15-S21. [CrossRef]

85. World Heart Federation. Obesity. Cardiovascular Risk Factors. World Heart Federation. 2016. Available online: http://www. world-heart-federation.org/cardiovascular-health/cardiovascular-disease-risk-factors/obesity/ (accessed on 27 October 2021).

86. Cheung, B.M.; Li, C. Diabetes and hypertension: Is there a common metabolic pathway? Curr. Atheroscler Rep. 2012, 14, 160-166. [CrossRef]

87. DeMarco, V.G.; Aroor, A.R.; Sowers, J.R. The pathophysiology of hypertension in patients with obesity. Nat. Rev. Endocrinol. 2014, 10, 364-376. [CrossRef]

88. UnitedNations. Sustainable Development Goals Report. 2021. Available online: https://unstats.un.org/sdgs/report/2021/ (accessed on 3 November 2021). 